\title{
The Expression of Human Telomerase Reverse Transcriptase Gene and Its Activity in Patients with B-Cell Chronic Lymphocytic Leukemia and Its Impact on Clinical Staging
}

\author{
Ali AlJabban ${ }^{1} \&$ Jaffar Alalsaidissa ${ }^{1}$ \\ ${ }^{1}$ Department of Pathology, Collage of Medicine, University of Baghdad, Iraq \\ Correspondence: Ali AlJabban, Department of Pathology, Collage of medicine, University of Baghdad, Iraq. Tel: \\ 964-770-605-6226. E-mail: aliabdalmhsen@yahoo.com
}

Received: February 15, 2018 Accepted: April 2, 2018 Online Published: April 19, 2018

doi:10.5539/gjhs.v10n5p167 URL: https://doi.org/10.5539/gjhs.v10n5p167

\begin{abstract}
Background: The B-Cell chronic lymphocytic leukemia is a commonest leukemia in elderly individuals characterized by progressive accumulation of mature lymphocyte in bone marrow and peripheral blood that tend to be immortal. The identification of human telomerase reverse transcriptase (hTERT) has been correlated with disease aggressiveness in malignancies. The previous researchers showed that the hTERT expression could serve as a molecular prognostic marker for B-CLL patients. However, due to the disease differences in prevalence and aggressiveness between the western and eastern countries, there is still a need to see the correlation of hTERT in B-CLL patients of the eastern world.
\end{abstract}

Aim: To test the quantitative assessment of hTERT gene expression in B-CLL patients and its prognostic value in correlation with clinical staging of disease in Iraqi patients.

Patients and Methods: we used the TRAP assay to assess the hTERT gene expression in mononuclear blood cells from 43 B-CLL patients.

Results: The hTERT gene expression was detected in $79.1 \%$ of B-CLL patients and no positive expression in control group $(\mathrm{P}=0.001)$. The hTERT gene expression tends to be significantly higher in advanced $\mathrm{B}-\mathrm{CLL}$ stage $(\mathrm{P}=0.0001)$. Also, the expression was higher among elderly patients, patients with lower hematological parameters, patients with splenomegaly or hepatomegaly, patients with a history of hypertension or diabetes mellitus, and patients with high immunophenotype score.

Conclusion: Our research suggests that the hTERT expression could serve as a prognostic marker for Iraqi patients with B-CLL as well as western countries.

Keywords: B-CLL, telomerase, hTERT, B-CLL prognosis, TRAP assay

\section{Introduction}

Chronic lymphocytic leukemia is a type of cancer affecting the white blood cells in adults (Hoff brand \& Moss, 2016). It is characterized by progressive accumulation of mature lymphocyte in bone marrow and peripheral blood. In chronic lymphocytic leukemia, B cells grow in an uncontrolled manner and accumulate in the bone marrow and blood, where they crowd out healthy blood cells (Swerdlow et al., 2016). Chronic lymphocytic leukemia is the most common type of leukemia accounting for $60 \%$ of cases, and it is the most common in the West counters (Teras et al., 2016) representing about $25 \%$ of all leukemia in adult's age above 50 years; however, in rare cases, it can be present in younger age (Kipps et al., 2017).

Telomerase reverse transcriptase it is a catalytic subunit of the enzyme telomerase, which, together with the telomerase RNA component (TERC), comprises the most important unit of the telomerase complex (Kirkpatrick, 2001; Skvortsov, 2011).

TERT is responsible for catalyzing the addition of nucleotides in a TTAGGG sequence to the ends of a chromosome's telomeres. This addition of repetitive DNA sequences prevents degradation of the chromosomal ends following multiple rounds of replication (Poole, Andrews, \& Tollefsbol, 2001).

The hTERT gene, located on chromosome 5, consists of 16 exons and 15 introns spanning $35 \mathrm{~kb}$. The core 
promoter of hTERT includes 330 base pairs upstream of the translation start site, as well as 37 base pairs of exon 2 of the hTERT gene (MacNeil, Bensoussan, \& Autexier, 2016). The hTERT promoter is GC-rich and lacks TATA and CAAT boxes but contains many sites for several transcription factors giving an indication of a high level of regulation by multiple factors in many cellular contexts (Akincilar, Unal, \& Tergaonkar, 2016).

Telomerase activity has been found in almost $85 \%$ of the most common cancers such as lung, breast, prostate, liver, and colon cancers. In addition, several studies showed that the level of telomerase activity was associated with poor prognosis of the patients (Shay, 2016).

\section{Material and Methods}

This is a prospective study that recruited patients visiting hematology ward/outpatients in Baghdad teaching hospital / medical city with laboratory and flow cytometry diagnosed B-CLL patients during the period from September 2017 to January 2018. The ethical committee approved this research at the College of Medicine, University of Baghdad, and informed consents were obtained from all participants.

Whole blood samples drawn from 43 B-CLL patients were collected at the time of diagnosis and before the treatment initiation. Whole blood samples were drawn from 20 control individuals that matched age and sex were also collected.

Inclusion criteria:

1) Patients diagnosed with B-CLL according to iwCLL criteria (Hallek et al. 2018) Figure 1.

2) Don't receive any medication for B-CLL
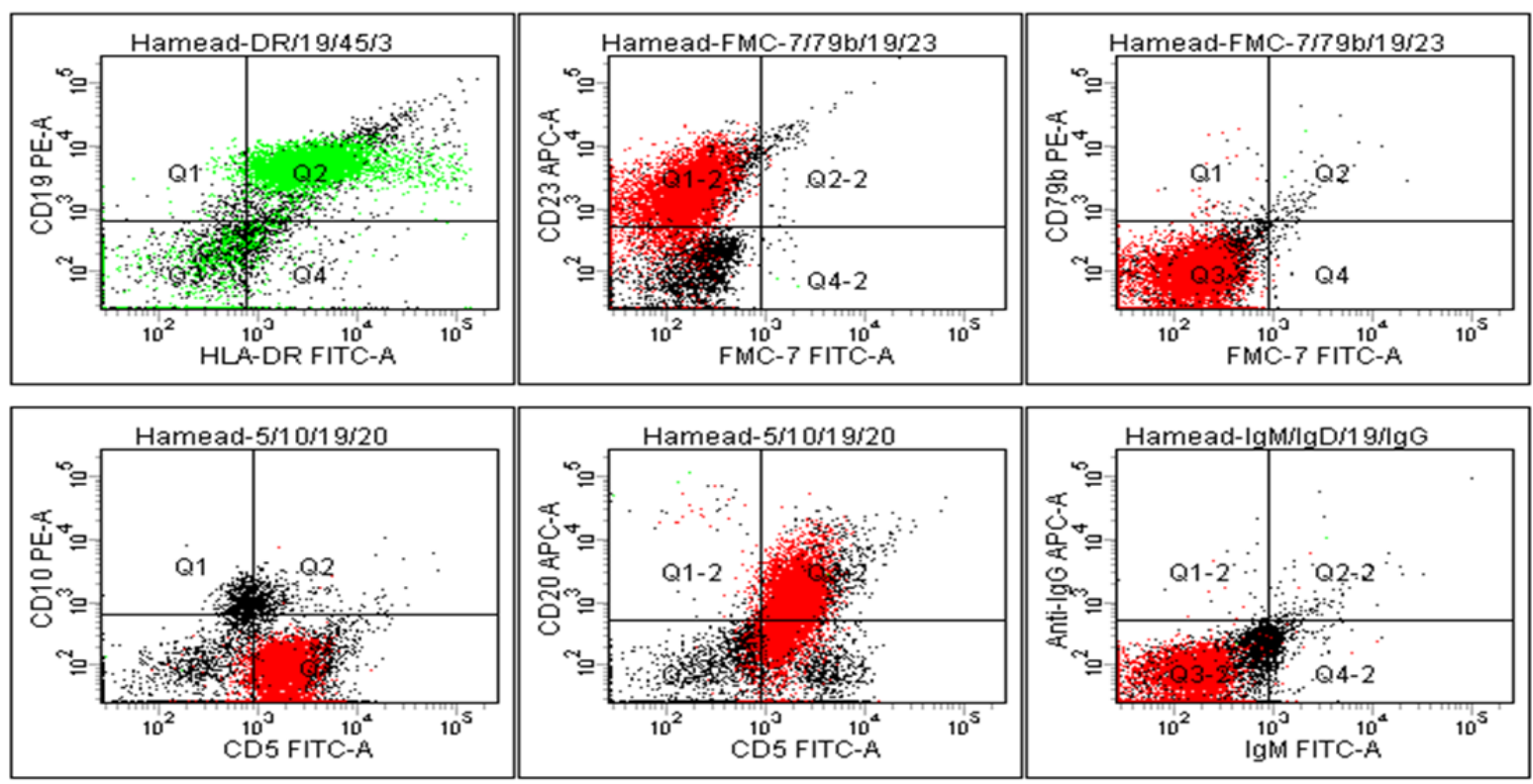

Figure 1. Flowcytometric analysia of peripheral blood sample from patient involved in this research showed positive expression of HLA-DR, CD19, CD5, and CD23, and negative expression of CD79b, CD10, FMC-7, and IgM. This patient diagnosed with B-CLL with IPT score 5

\subsection{Method}

The detection of telomerase activity is done by using Repeated Amplification Protocol (TRAP) method to detected hTERT telomerase activity in B-CLL patients (Mender \& Shay, 2015). Utilizing the Telomeric Repeat Amplification Protocol was done by photometric enzyme immunoassay kit called Telo TAGGG Telomerase PCR ELISA, developed by Roche applied science.

\subsection{Interpretation of the Results}

Absorbance values are reported as the A450 nm reading against a blank (reference wavelength A690nm). The Subtraction of the mean of the absorbance readings of the negative controls from those of the samples, samples are regarded as telomerase-positive if the difference in absorbance $(\Delta \mathrm{A})$ is higher than $0.2 \mathrm{~A}_{450 \mathrm{~nm}}-\mathrm{A}_{690 \mathrm{~nm}}$ units. 


\subsection{Statistical Analysis}

In this study, Statistical Package of Social Science (SPSS) version 23 software was used to present, describe and analyze data. Numeric variables were described using mean, median, minimum and maximum, as well as standard deviation (SD). Categorical variables were expressed as frequency (number) and percentage out of the total. Association between categorical variables was tested using Pearson's chi-square and Fisher exact test. Independent sample student t-test was used to compare the mean if continuous variables between groups. Specific test used to compare non-numeric data. In all statistical analyses, a P value of $(\leq 0.05)$ was considered to be significant.

\section{Results}

Out of 43 patients with B-CLL, 27 were males $(62.8 \%)$ and 16 were females $(37.2 \%)$ with a male to female ratio of 1.8:1. Patient's age was ranged between 28 and 80 years with a mean age of $58.77 \pm 12.05$ years and the median age of 61.00 years.

The mean age for the males was $60.59 \pm 11.49$ years while that for the female was $55.69 \pm 12.73$ years. No significant difference was found between the mean age of male and that for female patients ( $\mathrm{P}$ value $=0.224$ ). Overall $22(51.2 \%)$ patients were above 60 years and remaining, $21(48.8 \%)$ patients were $\leq 60$ years.

In this research 20 individuals were included as a control group, 13 males (65\%) and 7 females (35\%). Age ranged between 20 and 85 years. The mean age of control group was $59.6 \pm 14.3$ years.

The history of hypertension, diabetes mellitus, cancers, and infections were in 21 (48.8\%), 17 (39.5\%), 1 (2.3\%), and $8(18.6 \%)$ patients respectively. There was no significant difference between past medical history and age, genders and presenting symptoms.

In control group, the history of hypertension and diabetes mellitus were in $8(40 \%)$ and $6(30 \%)$ patients respectively.

The lymphadenopathy was detected in all patients while the splenomegaly and hepatomegaly were in 40 (93\%) and $26(60.5 \%)$ patients respectively (Figure 2 ).

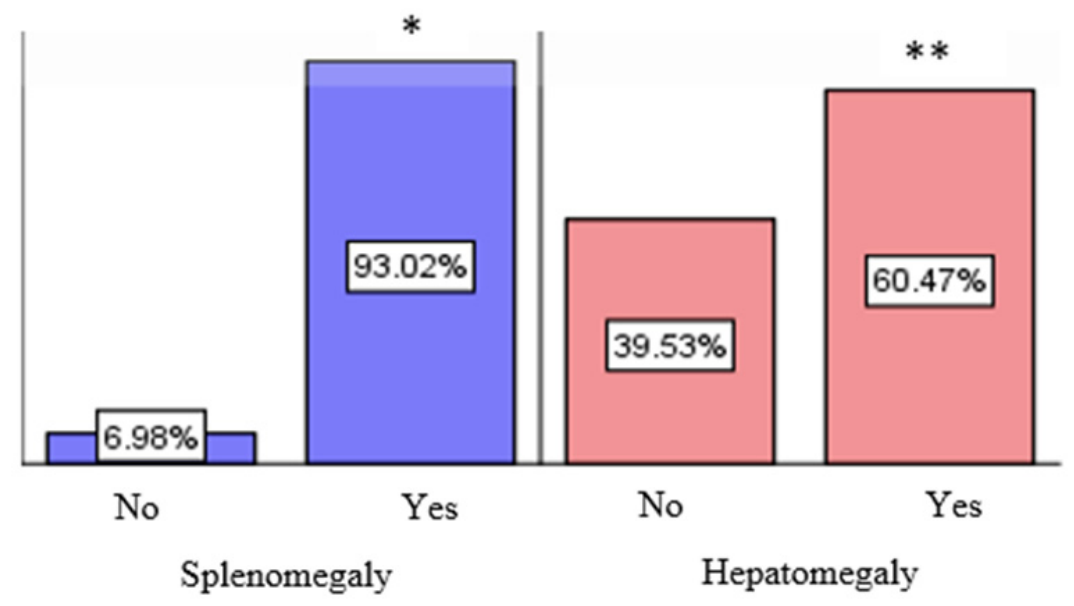

Figure 2. The percentage of patients had splenomegaly and hepatomegaly. * $\mathrm{P}=0.001, * * \mathrm{P}=0.22$ (one sample binominal test)

The mean hemoglobin in B-CLL patients was $11.87 \pm 2.15 \mathrm{~g} / \mathrm{dl}$ with mean MCV level of $89.87 \pm 8.21 \mathrm{fl}$. The mean total WBC count was $44.57 \pm 37.85 \times 10^{9} / 1$. The mean of neutrophils and lymphocytes count were $6.79 \pm 5.73$ and $32.86 \pm 28 \times 10^{9} / 1$ respectively. The mean of platelets count was $151.19 \pm 90.80 \times 10^{9} / 1$. Anemia $(\mathrm{Hb}<10.0 \mathrm{~g} / \mathrm{dl})$ was noted in 8 out $43\left(18.6 \%\right.$ ) patients. Leukocytosis (WBC count $\left.>11.0 \times 10^{9} / 1\right)$ was seen in 40 out $43(93 \%)$ patients. Lymphocytosis (lymphocytes count $>5 \times 10^{9} / 1$ ) was found in ALL patients and its 25, 50, 75 percentiles were $\left(9.7,23.5\right.$, and 49.4 respectively). Neutrophilia (neutrophils count $\left.>8 \times 10^{9} / 1\right)$ was seen in 15 out $43(34.9 \%)$ patients. Thrombocytopenia (platelet count $\left.<150 \times 10^{9} / 1\right)$ was seen in $27(62.8 \%)$ patients. 
Table 1. The hematological characterization of B-CLL patients

\begin{tabular}{llllllll}
\hline & RBC & Hb & MCV & WBC & $\begin{array}{l}\text { Neutrophil } \\
\text { count }\end{array}$ & $\begin{array}{l}\text { Lymphocyte } \\
\text { count }\end{array}$ & PTL count \\
\hline Mean & 3.70 & 11.87 & 89.87 & 44.57 & 6.79 & 32.86 & 151.19 \\
Median & 4.00 & 12.10 & 88.00 & 35.00 & 6.10 & 23.50 & 133.00 \\
SD & 0.91 & 2.15 & 8.21 & 37.85 & 5.73 & 28.00 & 90.80 \\
Minimum & 1.00 & 6.00 & 75.00 & 3.30 & 0.20 & 6.40 & 22.00 \\
Maximum & 5.00 & 15.10 & 114.00 & 173.00 & 33.90 & 114.00 & 547.00 \\
\hline
\end{tabular}

In control group, the mean $\mathrm{Hb}$ level was $12.42 \pm 2.65 \mathrm{~g} / \mathrm{dl}$ and the mean WBC count was $8.16 \pm 3.56 \times 10^{9} / 1$ while the platelet count was $154.43 \pm 89.13 \times 10^{9} / 1$.

In this research, we used modified Rai for classification. There was $22(51.2 \%)$ patients had an intermediate stage and $21(48.8 \%)$ patients had the high stage. No significant difference was observed between male and female in modified Rai classification. The majority of patients $29(67.4 \%)$ had score 5 in IPT score, followed by score 4 in 10 $(23.3 \%)$ patients. There was $3(7 \%)$ patients had score 3 and only one $(2.3 \%)$ patient had score 2 in IPT score.

In this research, hTERT gene expression (absorbance) was identified in 34 (79.1\%) out of 43 B-CLL patients (Table 2), while all control individuals show no gene expression. There was a statistically significant higher level of hTERT gene expression in B-CLL patients than control individuals $(\mathrm{P}=0.0001)$.

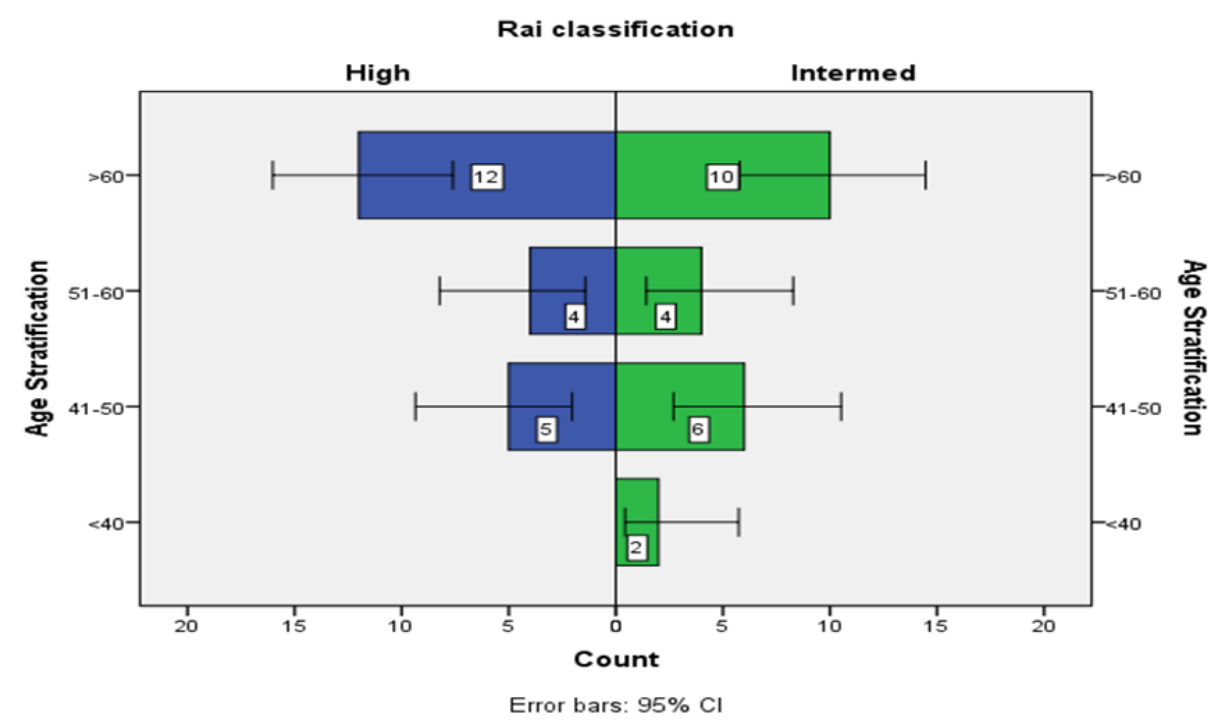

Figure 3. The distribution of modified Rai stages in association with age stratification

The mean hTERT absorbance was higher in patients aged $>60$ years than in patients aged $\leq 60$ years $[2.6$ and 2.03 absorbance respectively], and in males compared to females (3.08 and 2.88 absorbance respectively) among positive hTERT expression group. However, this difference did not reach statistical difference.

The mean hTERT absorbance was significantly higher (Independent samples Mann-Whitney U test) in patients with a history of hypertension and diabetes mellitus [(2.93 $\pm 1.16,3.06 \pm 1.22),(\mathrm{P}=0.022 ; \mathrm{P}=0.004)$ respectively]. 
Table 2. Analysis of hTERT expression in B-CLL patients

\begin{tabular}{llll}
\hline & & hTERT expression & \\
\cline { 2 - 4 } & Negative & Positive & P* Value \\
\hline Mean & 0.09 & 3.01 & $\mathbf{0 . 0 0 0 0 1}$ \\
Median & 0.08 & 3.21 & \\
Std. Deviation & 0.05 & 0.77 & \\
Minimum & 0.00 & 1.76 & \\
Maximum & 0.18 & 4.88 & \\
\hline
\end{tabular}

*One sample T test.

Mean of $\mathrm{Hb}, \mathrm{WBC}$, neutrophil, and lymphocyte counts were non-significantly lower in patients with positive hTERT absorbance, while platelets count was significantly lower in patients with positive hTERT absorbance $(\mathrm{P}=0.046)$ (Table 3).

Table 3. Hematological parameters in association with hTERT absorbance

\begin{tabular}{lccc}
\hline & \multicolumn{2}{c}{ hTERT absorbance } & \\
\cline { 2 - 3 } & Negative & P* value \\
& Mean & Mean & \\
\hline $\mathrm{Hb}$ & 12.9 & 11.6 & 0.08 \\
$\mathrm{WBC}$ & 70.0 & 37.8 & 0.11 \\
Neutrophil count & 6.9 & 6.8 & 0.69 \\
Lymphocyte count & 42.9 & 30.2 & 0.28 \\
PTL count & 173 & 145 & $\mathbf{0 . 0 4 6}$ \\
\hline
\end{tabular}

* Independent samples Mann-Whitney U test.

The hTERT absorbance was significantly frequent in high stage group than intermediate group $(\mathrm{P}=0.001)$.

Table 4. Modified Rai classification according to hTERT expression

\begin{tabular}{ccccc}
\hline & & \multicolumn{2}{c}{ Final Results } & Total \\
\cline { 3 - 4 } & & Negative & Positive & \\
\hline \multirow{2}{*}{ Modified Rai classification } & High & 0 & 21 & 21 \\
& Intermediate & 9 & 13 & 22 \\
\hline & & 9 & 34 & 43 \\
\hline
\end{tabular}

The mean hTERT absorbance was significantly higher among high stage group than intermediate group (3.47 \pm 0.46 and $2.26 \pm 0.53$ respectively) $(\mathrm{P}=0.0001)$.

The hTERT absorbance mean was higher with score 5 following by score 4 , score 3 , and score $2(3.17 \pm 0.75$, $2.87 \pm 0.73,2.46 \pm 0.91,2.23 \pm 0.0)$ respectively. However, this difference did not reach statistical difference $(\mathrm{P}=0.67)$.

\section{Discussion}

In this research, the mean of age was $58.77 \pm 12.05$ with a range between 28 and 80 years. This result was similar to that of Alaadin S. Naji (Naji, 2012) in Iraq and the median age tends to be higher in western countries (Eichhorst, 2015; Parikh, 2014). This disparity may be related to the effect of geographical and environmental factors especially the multiple wars that happened in Iraq that made the mean age of patients is younger than that in 
western countries.

Our result showed a higher number of patients in stage B and C than the result of western countries (Call, 2014; Langerbeins, 2016).This disparity may be related to the advanced health system in western countries that they diagnosed patients in early stages of disease and in Iraq we need to increase the patient's awareness of importance of early diagnoses also we need to adopt a new classification system to involve biomarker in staging rather than depend solely on patient's examinations and CBC.

The hTERT expression is strongly associated with the telomerase activity and thus it had been used to assess the telomerase activity in various studies and publications (Patrick, Cheng, An, \& Weng, 2017). Hence in this study, we used hTERT detection to assess the telomerase activity by TRAP assay in both B-CLL patients and control individuals, and it showed that the hTERT expression detected in $34(79.1 \%)$ patients and it was significantly higher than the control group which did not show any hTERT expression and this result is higher than Tchirkov A (Tchirkov, 2004) result which showed 59\% of B-CLL patients expressed hTERT and this disparity may be related to difference between the methods that used for hTERT detection. Also, the hTERT expression in our research is correlated with other researchers that identified hTERT expression in patients malignancy in compared to normal individuals (Ropio, 2016; Bruedigam, 2016).

This gives us a strong evidence that hTERT could be used as a pan-cancer marker to assess the different type of malignancies included B-CLL patients also it is optional future pan therapy for a different type of malignancies. From our research, we can identify that the hTERT could be used as a marker for diagnosis of difficult cases. All B-CLL patients with high Rai stage have positive hTERT expression and this was significantly higher than patients with intermediate Rai stage.

Also, this research showed that the hTERT is higher in patients with advanced age and this is could explain by the fact that the older aged had short telomere and thus need more telomerase activity. There was no significant difference in the expression of hTERT between the different clinical presentation, splenomegaly, and hepatomegaly. However, we found the hTERT was significantly higher in patients with a history of hypertension or diabetes mellitus. In Liebermann research, he described the association between the placental hTERT expression and hypertensive disorders of pregnancy (Liebermann, 2010). This coincidental finding raises the awareness of hTERT expression and its correlation with hypertension or diabetes mellitus patients.

$\mathrm{The} \mathrm{Hb}, \mathrm{WBC}$, neutrophil, lymphocyte, and platelet counts were lower in patients with positive hTERT expression. This is may explain by two ways: firstly: because the expression of hTERT is associated with advanced age and the advanced age may contribute to the lower hematological parameters, secondly: the hTERT expression increase the survival of cells so that the bone marrow down regulate itself for producing new cell populations. Also, the advanced age and stage of B-CLL patients may contribute to bone marrow infiltration by malignant cells. Thus we need more study in term of identifying specifically the cell line that produces a high level of hTERT expression.

The mean hTERT expression was higher in patients with IPT score 5 followed by score 4, 3, 2 respectively. This disparity in hTERT expression among IPT scores may relate to that the expression of hTERT tends to be high in typical B-CLL patients that had IPT score 4-5 rather than the patients with IPT 2-3 score.

It is easy to predict from this research that the hTERT expression associated with advanced stage B-CLL patients as in previous studies, but the question here: Is the high expression of hTERT in some intermediate stage B-CLL patients will behave as an advanced stage? And shall we rely on clinical staging only or we need to add new markers like hTERT to the staging system?

\section{Conclusions}

1) The hTERT expression was significantly highly associated with B-cell chronic lymphocytic leukemia patients. Also, it was significantly associated with modified Rai high stage B-cell chronic lymphocytic leukemia patients and it was higher than previous studies in western countries.

2) The hTERT was high in advanced patients' age and high IPT score patients, in B-CLL patients with lower hematological parameters, and patients had a history of hypertension or diabetes mellitus.

\section{Competing Interests Statement}

The authors declare that there are no competing or potential conflicts of interest.

\section{References}

Akincilar, S. C., Unal, B., \& Tergaonkar, V. (2016). Reactivation of telomerase in cancer. Cellular and Molecular Life Sciences, 73, 1659-1670. https://doi.org/10.1007/s00018-016-2146-9 
Bruedigam, C., \& Lane, S. W. (2016). Telomerase in hematologic malignancies. Current. Opinion in Hematology, 23(4), 346-53. https://doi.org/10.1097/MOH.0000000000000252

Call, T. G., Norman, A. D., Hanson, C. A., Achenbach, S. J., Kay, N. E., Zent, C. S., ... \& Hallberg, E. J. (2014). Incidence of chronic lymphocytic leukemia and high - count monoclonal B - cell lymphocytosis using the 2008 guidelines. Cancer, 120(13), 2000-2005. https://doi.org/10.1002/cncr.28690

Eichhorst, B., Robak, T., Montserrat, E., Ghia, P., Hillmen, P., Hallek, M., \& Buske, C. (2015). Chronic lymphocytic leukaemia: ESMO Clinical Practice Guidelines for diagnosis, treatment and follow-up. Annals of Oncology, 26(suppl_5), 78-84. https://doi.org/10.1093/annonc/mdv303

Geifman-Holtzman, O., Xiong, Y., Holtzman, E. J., Hoffman, B., Gaughan, J., \& Liebermann, D. A. (2010). Increased placental telomerase mRNA in hypertensive disorders of pregnancy. Hypertension in pregnancy, 29(4), 434-445. https://doi.org/10.3109/10641950903214625

Hallek, M., Cheson, B. D., Catovsky, D., Caligaris-Cappio, F., Dighiero, G., Döhner, H., ... \& Kipps, T. J. (2008). Guidelines for the diagnosis and treatment of chronic lymphocytic leukemia: a report from the International Workshop on Chronic Lymphocytic Leukemia updating the National Cancer Institute-Working Group 1996 guidelines. Blood, 111(12), 5446-5456. https://doi.org/10.1182/blood-2007-06-093906

Hoffbrand, A. V., \& Moss, P. A. (2016). Essential haematology. Oxford: A John Wiley \& Sons, Ltd., Publication. Retrieved from www.wiley.com/go/essentialhaematology

Kipps, T. J., Stevenson, F. K., Wu, C. J., Croce, C. M., Packham, G., Wierda, W. G., ... \& Rai, K. (2017). Chronic lymphocytic leukaemia. Nature Reviews Disease Primers, 3, 16096. https://doi.org/10.1038/nrdp.2017.8

Kirkpatrick, K. L., \& Mokbel, K. (2001). The significance of human telomerase reverse transcriptase (hTERT) in cancer. European Journal of Surgical Oncology, 27(8), 754-760. https://doi.org/10.1053/ejso.2001.1151

Langerbeins, P., Groß-Ophoff-Müller, C., \& Herling, C. D. (2016). Risk-adapted therapy in early-stage chronic lymphocytic leukemia. Oncology research and treatment, 39(1-2), 18-24. https://doi.org/10.1159/000443013

MacNeil, D. E., Bensoussan, H. J., \& Autexier, C. (2016). Telomerase regulation from beginning to the end. Genes, 7(9), 64. https://doi.org/10.3390/genes7090064

Mender, I., \& Shay, J. W. (2015). Telomerase Repeated Amplification Protocol (TRAP). Bio-Protocol, 5(22), e1657. https://doi.org/10.21769/BioProtoc. 1657

Naji, A. S., \& FICMS, F. (2012). Outcome of 49 Iraqi adult patients with Chronic Lymphocytic Leukemia treated with oral alkylating agent. J Fac Med Baghdad, 54(2).

Parikh, S. A., Rabe, K. G., Kay, N. E., Call, T. G., Ding, W., Schwager, S. M., ... Shanafelt, T. D. (2014). Chronic lymphocytic leukemia in young $(\leq 55$ years) patients: a comprehensive analysis of prognostic factors and outcomes. Haematologica, 99(1), 140-147. https://doi.org/10.3324/haematol.2013.086066

Patrick, M. S., Cheng, N., An, J., \& Weng, N. (2017). Quantification of hTERT alternatively spliced isoforms in resting and activated human T cell subsets. Journal of Immunology, 198(74), 6.

Poole, J. C., Andrews, L. G., \& Tollefsbol, T. O. (2001). Activity, function, and gene regulation of the catalytic subunit of telomerase (hTERT). Gene, 269(1-2), 1-12. https://doi.org/10.1016/S0378-1119 (01)00440-1.

Ropio, J., Merlio, J., Soares, P., \& Chevret, E. (2016). Telomerase Activation in Hematological Malignancies. Genes, 7(9), 61. https://doi.org/10.3390/genes7090061

Shay, J. W. (2016). Role of Telomeres and Telomerase in Aging and Cancer. Cancer Discovery, 6(6), $584-593$. https://doi.org/10.1158/2159-8290.CD-16-0062

Skvortsov, D. A., Zvereva, M. E., Shpanchenko, O. V., \& Dontsova, O. A. (2011). Assays for Detection of Telomerase Activity. Acta Naturae, 3(1), 48-68.

Swerdlow, S. H., Campo, E., Pileri, S. A., Harris, N. L., Stein, H., Siebert, R., ... \& Jaffe, E. S. (2016). The 2016 revision of the World Health Organization classification of lymphoid neoplasms. Blood, 127(20), 2375-2390. https://doi.org/10.1182/blood-2016-01-643569

Tchirkov, A., Chaleteix, C., Magnac, C., Vasconcelos, Y., Davi, F., Michel, A., ... \& Travade, P. (2004). hTERT expression and prognosis in B-chronic lymphocytic leukemia. Annals of Oncology, 15(10), 1476-1480. https://doi.org/10.1093/annonc/mdh389

Teras, L. R., DeSantis, C. E., Cerhan, J. R., Morton, L. M., Jemal, A., \& Flowers, C. R. (2016). 2016 US lymphoid 
malignancy statistics by World Health Organization subtypes. CA: a cancer journal for clinicians, 66(6), 443-459. https://doi.org/10.3322/caac.21357

\section{Copyrights}

Copyright for this article is retained by the author(s), with first publication rights granted to the journal.

This is an open-access article distributed under the terms and conditions of the Creative Commons Attribution license (http://creativecommons.org/licenses/by/4.0/). 